\title{
Report on Properties and Microstructure of 3D Printed Inconel 718
}

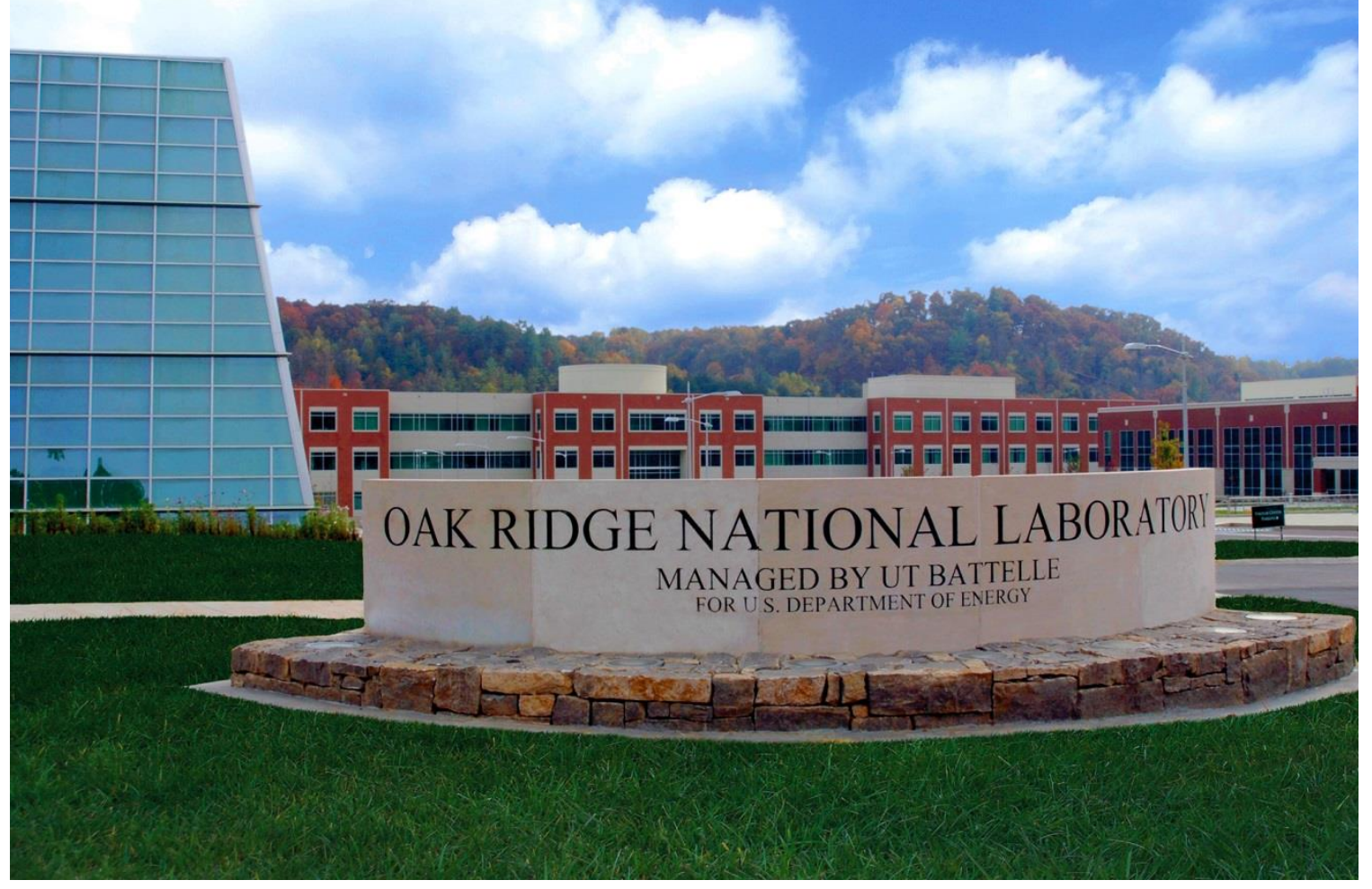

Stephen Taller

Ty Austin

Vincent Paquit

Kurt Terrani

August 2021

M3TC-21OR0403033 


\title{
DOCUMENT AVAILABILITY
}

Reports produced after January 1, 1996, are generally available free via US Department of Energy (DOE) SciTech Connect.

Website www.osti.gov

Reports produced before January 1, 1996, may be purchased by members of the public from the following source:

\author{
National Technical Information Service \\ 5285 Port Royal Road \\ Springfield, VA 22161 \\ Telephone 703-605-6000 (1-800-553-6847) \\ TDD 703-487-4639 \\ Fax 703-605-6900 \\ E-mail info@ntis.gov \\ Website http://classic.ntis.gov/
}

Reports are available to DOE employees, DOE contractors, Energy Technology Data Exchange representatives, and International Nuclear Information System representatives from the following source:

Office of Scientific and Technical Information

PO Box 62

Oak Ridge, TN 37831

Telephone 865-576-8401

Fax 865-576-5728

E-mail reports@osti.gov

Website http://www.osti.gov/

This report was prepared as an account of work sponsored by an agency of the United States Government. Neither the United States Government nor any agency thereof, nor any of their employees, makes any warranty, express or implied, or assumes any legal liability or responsibility for the accuracy, completeness, or usefulness of any information, apparatus, product, or process disclosed, or represents that its use would not infringe privately owned rights. Reference herein to any specific commercial product, process, or service by trade name, trademark, manufacturer, or otherwise, does not necessarily constitute or imply its endorsement, recommendation, or favoring by the United States Government or any agency thereof. The views and opinions of authors expressed herein do not necessarily state or reflect those of the United States Government or any agency thereof. 


\title{
REPORT ON PROPERTIES AND MICROSTRUCTURE OF 3D PRINTED INCONEL 718
}

\author{
Stephen Taller ${ }^{1}$ \\ Ty Austin ${ }^{1,2}$ \\ Vincent Paquit ${ }^{1}$ \\ Kurt Terrani ${ }^{3}$
}

${ }^{1}$ Oak Ridge National Laboratory

${ }^{2}$ University of Tennessee, Knoxville

${ }^{3}$ Formerly Oak Ridge National Laboratory

August 2021

M3TC-21OR0403033

Prepared by

OAK RIDGE NATIONAL LABORATORY

Oak Ridge, TN 37831-6283

managed by

UT-BATTELLE LLC

for the

US DEPARTMENT OF ENERGY

under contract DE-AC05-00OR22725 


\section{CONTENTS}

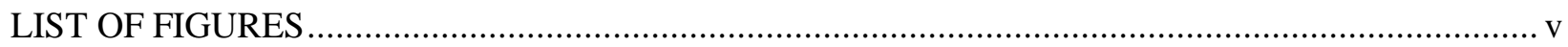

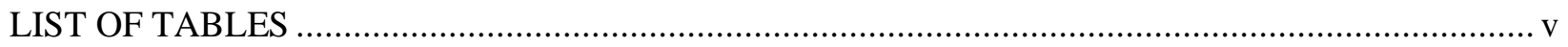

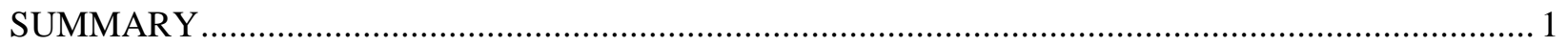

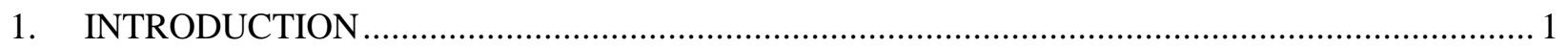

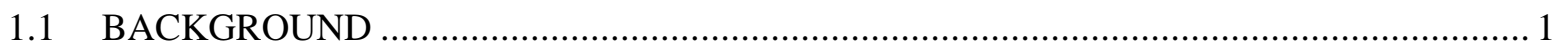

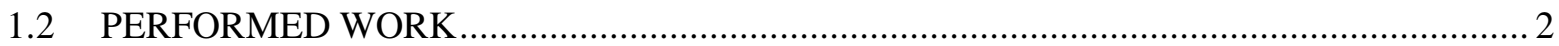

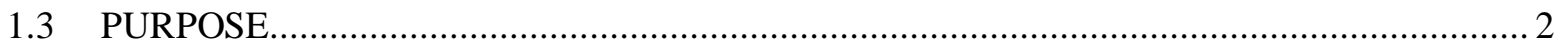

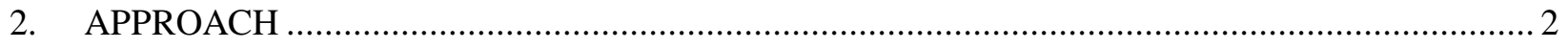

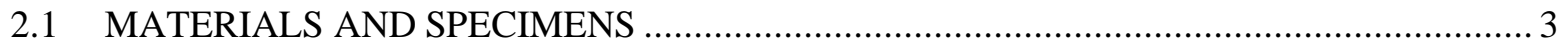

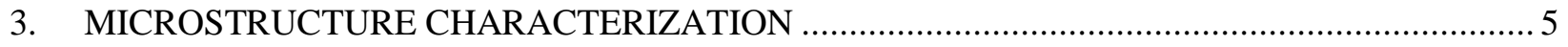

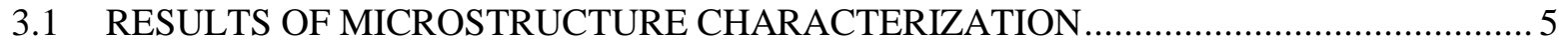

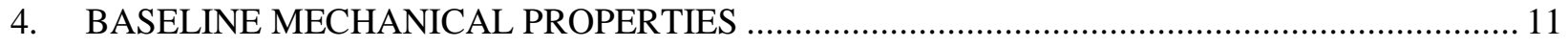

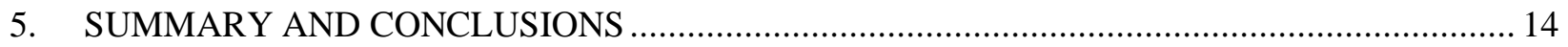

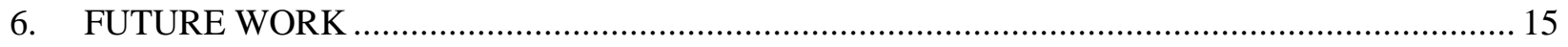

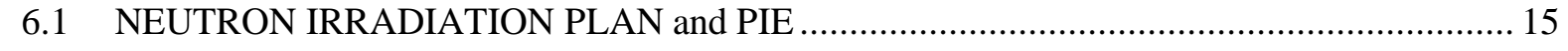

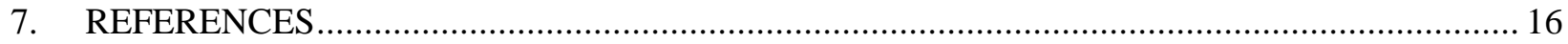





\section{LIST OF FIGURES}

Figure 1. Experimental approach to determining the contribution of each precipitate phase to the properties of AM Inconel 718.

Figure 2. Photo of the AM-produced superalloy 718 for property determination and microstructure characterization.

Figure 3. STEM images of ASB AM Inconel 718 showing dendritic Laves phase, large $\delta$ precipitates, TiC, pores, oxide particles, and $\gamma^{\prime}$ and $\gamma^{\prime \prime}$ precipitates.

Figure 4. STEM images of ASB AM Inconel 718 with corresponding EDS maps for precipitateforming elements showing large $\delta$ precipitates $\left(\mathrm{Ni}_{3} \mathrm{Nb}\right)$, Laves particles (Nb-Mo-Si rich), $\mathrm{TiC}$, and $\gamma^{\prime \prime}$ precipitates $\left(\mathrm{Ni}_{3} \mathrm{Nb}\right)$.

Figure 5. Higher magnification STEM images of ASB AM Inconel 718 with corresponding EDS maps for precipitate forming elements showing $\gamma^{\prime}\left(\mathrm{Ni}_{3}(\mathrm{Ti}, \mathrm{Al})\right)$ and $\gamma^{\prime \prime}\left(\mathrm{Ni}_{3} \mathrm{Nb}\right)$ precipitates.

Figure 6. Precipitate size distributions for $\gamma^{\prime}, \gamma^{\prime \prime}$, and $\delta$ phases in ASB AM Inconel 718.

Figure 7. STEM HAADF images of wrought Inconel 718, AM718-HT1, AM718-HT2, and AM718-HM showing the mixture of $\gamma^{\prime}, \gamma^{\prime \prime}$, and $\delta$ as bright features and oxides as dark features.

Figure 8. Precipitate size distributions for $\gamma^{\prime}, \gamma^{\prime \prime}$, and $\delta$ phases in heat-treated AM Inconel 718.

Figure 9. Representative engineering stress-strain curves for heat-treated AM Inconel 718 and wrought Inconel 718 at room temperature.

Figure 10. Individual engineering stress-strain curves for wrought Inconel 718 (a) and heattreated AM Inconel $718(\mathrm{~b}-\mathrm{d})$ at room temperature.

\section{LIST OF TABLES}

Table 1. Composition of superalloy 718 powder used for LPBF in wt \% provided by vendor Lot 119 and a commercially purchased wrought superalloy 718 for comparison measured with $\mathrm{x}$-ray fluorescence.....

Table 2. Heat treatments for AM718 and W718 to produce increasingly simpler microstructures for characterization and mechanical property measurement.

Table 3. Summary of characterization results for precipitate phases observed in ASB AM718.............. 8

Table 4. Summary of characterization results for precipitate phases observed in heat-treated AM718.

Table 5. Tensile tests conducted in FY21 of AM718 and W718 at room temperature and elevated temperatures.

Table 6. Engineering properties derived from room temperature tensile tests conducted in FY21 of wrought Inconel 718 and heat-treated AM Inconel 718.

Table 7. HFIR irradiation conditions for Inconel 718 as part of TCR. 



\section{SUMMARY}

The report presents the microstructure and mechanical properties of 3D printed Inconel 718 to assess its potential use as a structural material for the Transformation Challenge Reactor (TCR). The structural components near the outlet of the core will experience significant neutron fluxes and outlet coolant temperatures from the hot standby temperature of $300^{\circ} \mathrm{C}$ to nearly $550^{\circ} \mathrm{C}$ at the center of the part. These components must support the core in appropriate loading conditions and require structural analysis at relevant temperatures. Strong spatial and chemical heterogeneity was found in as-built (ASB) Inconel 718. Three heat treatments were designed and conducted to simplify the microstructure and determine how each precipitating phase contributed to the overall strength. Baseline mechanical properties were measured from uniaxial tensile tests on subsize SS-J2 specimens at room temperature and at elevated temperatures of 300,450 , and $600^{\circ} \mathrm{C}$. Microstructure electron microscopy was performed on ASB Inconel 718 and heat treated to correlate the observed mechanical properties with nanoscale features.

Homogenization of the microstructure led to a highly ductile Inconel with lower strength compared with wrought Inconel 718. The tensile properties of additively manufactured 718 using a standard ASTMrecommended heat treatment were consistent with literature and with the ASTM for the properties of this alloy. A higher fraction of the $\delta$ phase led to shorter uniform elongation without altering other engineering properties.

\section{INTRODUCTION}

\subsection{BACKGROUND}

Structural materials used in the development of high-temperature advanced reactors face many challenges, including irradiation effects, corrosion, and strength at temperatures ranging from 500 to $700^{\circ} \mathrm{C}$ [1]. Ni-based superalloys are a primary candidate alloy class for advanced reactor applications because of their intrinsic resistance to creep, their adequate resistance to corrosion, and the ability to tailor the microstructure for high strength [2]. These high-strength Ni-based alloys gain their strength primarily through solid solution strengthening and/or secondary precipitating phases in the lattice $[3,4]$ in the form of intermetallic phases $-\delta, \gamma^{\prime}$, or $\gamma^{\prime \prime}$ - or in a carbide phase. The poor machinability and extensive work hardening of Ni-based superalloys [5, 6] make them an attractive option for additive manufacturing (AM) to produce geometrically complex components with distinct microstructures while reducing the overall cost and shortening the supply chain.

Inconel 718 is a candidate alloy for several structural elements for the Transformation Challenge Reactor (TCR) below the core. Consistent with the overall expectation for superalloys in a nuclear reactor environment, superalloy 718 is compatible with the reactor coolant and in-vessel materials for TCR. The structural components near the core outlet will experience significant neutron fluxes and outlet coolant temperatures from the hot standby temperature of $300^{\circ} \mathrm{C}$ to nearly $550^{\circ} \mathrm{C}$ at the center of the part. These components must support the core in appropriate loading conditions and require structural analysis at relevant temperatures. For the TCR program, laser powder bed fusion (LPBF) is used to build parts through the sequential application of thin layers $(20-100 \mu \mathrm{m})$ of metal feedstock powder melted by a scanning laser, resulting in rapid solidification and thermal cycling. Despite the continual improvement in processing parameters, the microstructures of AM materials typically contain a high density of pores and other nonequilibrium features. The composition of superalloy 718 allows for the formation of many different precipitating phases, all of which could result from AM [7]. Several appear to be beneficial for the alloy at high temperatures $\left(\gamma^{\prime}\right.$ and $\left.\gamma^{\prime \prime}\right)$, whereas alternative phases ( $\delta$ and Laves) appear to be detrimental [8]. Therefore, knowing the properties and microstructure controlling the properties relevant to the TCR operating conditions is critical for evaluating superalloy 718 as a candidate alloy. 
However, there is very limited literature on the precipitate stability in Ni-based superalloys under irradiation. Traditionally, superalloy 718 has been irradiated in the precipitate-hardened condition with a $\gamma$ primary phase strengthened by $\gamma^{\prime}\left(\mathrm{Ni}_{3}(\mathrm{Al}, \mathrm{Ti})\right)$ and $\gamma^{\prime \prime}\left(\mathrm{Ni}_{3} \mathrm{Nb}\right)$ precipitates. In reactor irradiations, $\gamma^{\prime}$ coarsened at higher temperatures, precipitated at grain boundaries, and changed morphology from spherical precipitates to elongated structures in Ni-based alloy PE-16 $[9,10]$. With ion irradiation at a lower temperature $\left(360^{\circ} \mathrm{C}\right)$, the $\gamma^{\prime}$ precipitation was accelerated relative to aging at the same temperature [11], and radiation dissolved precipitates at $200^{\circ} \mathrm{C}$ and lower temperatures $[12,13]$. The AM process typically results in a $\gamma$ phase lattice with Laves phase $\left(\mathrm{Ni}_{2} \mathrm{Nb}\right)$ dendrites [14-18]. The Laves phase is generally considered to be detrimental to the mechanical properties of superalloy 718 [19]. The fraction of the Laves phase can be reduced by increasing the cooling rate during the AM fabrication process [15]. However, it is suggested that the Laves phase is an unavoidable terminal solidification phase when cooling through the liquidus and solidus lines [20] based on the welding behavior of alloy 718 [21]. There is very little irradiation knowledge on the radiation response of Laves or $\delta$, both of which compete with $\gamma^{\prime \prime}$ for $\mathrm{Nb}$. Thus, there is a scientific and technical objective to examine the roles of precipitates on the irradiated microstructure and mechanical properties using the AM process for potential reactor applications.

\subsection{PERFORMED WORK}

Materials testing tasks and characterization aimed to build a preliminary database for the mechanical properties of Inconel 718 produced through LPBF. Multiple sets of specimens have been manufactured and heat treated for mechanical tests before irradiation and for insertion into the High Flux Isotope Reactor (HFIR). Specimens of the SS-J2 miniature tensile geometry were manufactured from LPBFproduced blocks of superalloy 718. Transmission electron microscopy (TEM) and energy dispersive x-ray spectroscopy (EDS) characterized the microstructure at the nano- to micro-scales.

This report presents the preliminary microstructure characterization of 3D printed Inconel 718 and the approach taken to understand the mechanical properties measured. First, a summary of the approach taken to link the mechanical properties from tensile tests to the microstructure is presented, followed by a description of the microstructure characterization and uniaxial tensile testing. A description of the methods used for each task is included for reference. Finally, the preliminary baseline information is summarized, and the ongoing and future planned work is described.

\subsection{PURPOSE}

This document quantifies and summarizes the microstructure and mechanical properties of Inconel 718 produced by using an advanced manufacturing approach called LPBF. The property data are intended for use by the core component manufacturers, modelers, and reactor designers in the TCR program and by other researchers. The data can also be used in the design of advanced nuclear technology for which the material and manufacturing process presented within this report are of interest.

\section{APPROACH}

There is an inherent link between a material's microstructure and macroscopic mechanical properties. In the broadest sense, the yield strength of a material is the sum of the inherent strength from the crystal lattice, $\sigma_{Y, 0}$, with additional strength from the effects of defects and secondary phases, $\sigma_{D}$, as shown in Eq. (1). The inherent strengthening, shown in Eq. (2), stems from of the solid solutioning strength from substitutional elements in the face-centered cubic (FCC) Ni lattice, $\sigma_{S S}$; the grain boundaries through the Hall-Petch relationship, $\frac{k_{y}}{\sqrt{d}}$, where $k_{y}$ is a constant, and $d$ is the average grain diameter; and the dislocation friction stress, also known as the Peierls-Narbarro stress, $\tau_{P-N}$ [22]. The impact of defects and 
precipitates is generally described by the dispersed barrier hardening model (Eq. [3]), $\alpha_{i} M \mu b \sqrt{N_{i} d_{i}}$, where $\alpha$ represents the strength of the barrier, $M$ is the Taylor factor, $\mu$ is the shear modulus, $b$ is the Burgers vector, $N$ is the density of the precipitates, and $d$ is their size described as an equivalent diameter. As stated in the background, the composition of superalloy 718 allows for the formation of many different precipitating phases - $\gamma^{\prime}, \gamma^{\prime \prime}, \delta$, MX carbides, Laves - all of which can result from AM [7]. Additionally, the oxidation of the powder used for AM fabrication results in oxide particles dispersed throughout the material.

$$
\begin{gathered}
\sigma_{Y}=\sigma_{Y, 0}+\sigma_{D} \\
\sigma_{Y, 0}=\sigma_{S S}+\frac{k_{y}}{\sqrt{d}}+\tau_{P-N}, \\
\sigma_{D}=\sum_{i}^{\delta, \gamma^{\prime}, \gamma^{\prime \prime}, \text { Laves }, M X, \text { oxide }} \alpha_{i} M \mu b \sqrt{N_{i} d_{i}} .
\end{gathered}
$$

The inherent complexity in the microstructure of as-built (ASB) superalloy 718 will limit the utility of any measured properties to determine the physical origins of those properties. Several heat treatments were designed to simplify the microstructure through the removal and subsequent reprecipitation of strengthening phases. The approach taken in this work is summarized in Figure 1. The comparison of the properties of each heat treatment combined with a detailed microstructural characterization to determine the size and density of the precipitates will allow the strength of each precipitate to be calculated. The relative contribution of each phase to the strength of the ASB AM superalloy 718 can be estimated from the calculation and characterization of the ASB microstructure.

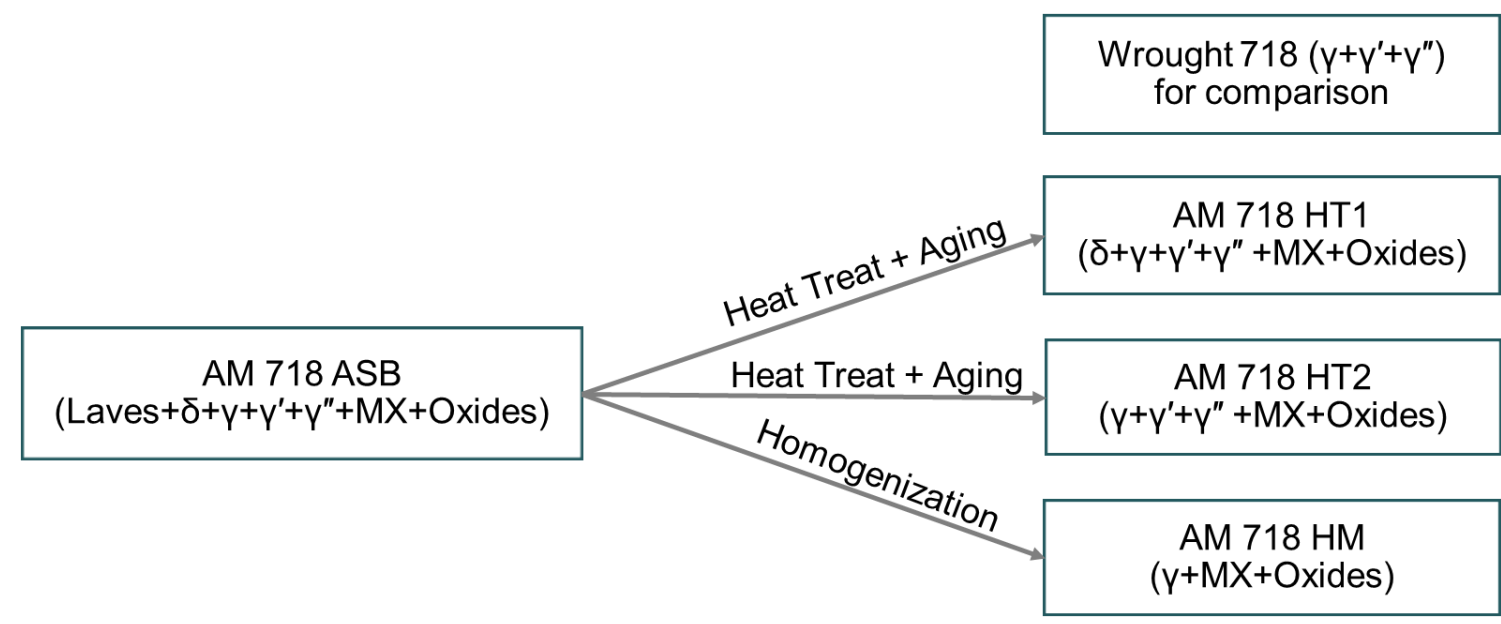

Figure 1. Experimental approach to determining the contribution of each precipitate phase to the properties of AM Inconel 718.

\subsection{MATERIALS AND SPECIMENS}

The Inconel 718 used in this investigation was printed in one build by using LPBF on the Concept X-Line 2000R at the Manufacturing Demonstration Facility (MDF) at Oak Ridge National Laboratory (ORNL) with a build ID of 20200206XL and a composition listed in Table 1. A reference photo for the plates produced is provided in Figure 2. For this report, samples were produced entirely from plate 9. The plate was sectioned into four pieces: three for subsequent heat treatments and one for the ASB microstructure. Three heat treatments of alloy 718 were designed to reduce the complexity of the AM microstructure and allow for comparative analysis of the microstructure and mechanical properties, and are summarized in Table 2. The initial homogenization treatment of $1,174^{\circ} \mathrm{C}$ for $2 \mathrm{~h}$ and $1,204^{\circ} \mathrm{C}$ for $6 \mathrm{~h}$ was chosen to remove 
all secondary phases, including the detrimental Laves phase that typically forms during AM and competes with $\delta, \gamma^{\prime}$, and $\gamma^{\prime \prime}$ precipitates for $\mathrm{Nb}$ [23]. This homogenization becomes a reference case, designated as AM718-HM, produced by annealing at $1,093^{\circ} \mathrm{C}$ with no additional heat treatments to have a solutionannealed alloy 718 without precipitates. The extensive knowledge of the precipitation in alloy 718 [24-28] led to the adoption of a standard heat treatment to produce $\delta$ precipitates that consist of solution annealing at $945^{\circ} \mathrm{C}$ followed by aging at $718^{\circ} \mathrm{C}$ and then $621^{\circ} \mathrm{C}$, shortened to $945^{\circ} \mathrm{C} / 718^{\circ} \mathrm{C} / 621^{\circ} \mathrm{C}[3,28,29]$, and designated as AM718-HT1. At higher temperatures, the formation of $\gamma^{\prime}$ and $\gamma^{\prime \prime}$ is favored over the formation of $\delta$ precipitates $[8,28,29]$. A higher temperature heat treatment of $1,093^{\circ} \mathrm{C} / 718^{\circ} \mathrm{C} / 621^{\circ} \mathrm{C}$ was chosen to form a large density of small $\gamma^{\prime}$ and $\gamma^{\prime \prime}$ precipitates, designated as AM718-HT2. A traditional wrought alloy 718 prepared according to ASTM specifications [30] will be used as a control and compared with the AM specimens. After heat treatment, specimens were fabricated into the form of SS-J2 subsize tensile specimens [31] for uniaxial tensile tests and standardized capsules [32] for insertion into HFIR with a gauge that was 5 $\mathrm{mm}$ long, $0.5 \mathrm{~mm}$ thick, and $1.2 \mathrm{~mm}$ wide. Each specimen was individually engraved via a laser with a unique ID for tracking from the original build plate to the tensile specimen.

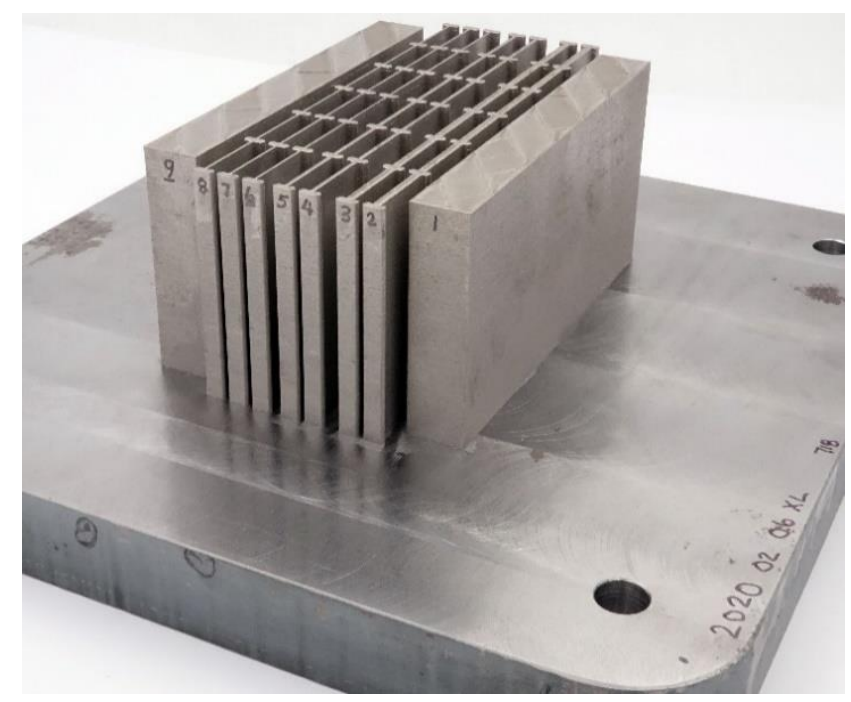

Figure 2. Photo of the AM-produced superalloy 718 for property determination and microstructure characterization.

Table 1. Composition of superalloy 718 powder used for LPBF in wt \% provided by vendor Lot 119 and a commercially purchased wrought superalloy 718 for comparison measured with $x$-ray fluorescence.

\begin{tabular}{|c|c|c|c|c|c|c|c|c|c|c|c|}
\hline Designation & Ni & Fe & Cr & Nb & Mo & Ti & Al & Si & C & N & O \\
\hline AM718-Lot 119 & Bal. & 18.22 & 18.99 & 5.15 & 3.0 & 0.93 & 0.50 & 0.04 & 0.04 & 0.012 & 0.016 \\
\hline W718-Z1653 & Bal. & 18.77 & 17.56 & 5.18 & 2.89 & 0.94 & 0.49 & 0.08 & 0.02 & - & - \\
\hline
\end{tabular}

Table 2. Heat treatments for AM718 and W718 to produce increasingly simpler microstructures for characterization and mechanical property measurement. The cooling between steps was performed using either water cooling (WC) or air cooling (AC).

\begin{tabular}{|l|c|c|c|c|c|c|c|c|}
\hline Designation & $\begin{array}{c}\text { Homogenization } \\
\left({ }^{\circ} \mathbf{C} / \mathbf{h}\right)\end{array}$ & Cooling & $\begin{array}{c}\text { Solution } \\
\text { anneal } \\
\left({ }^{\circ} \mathbf{C} / \mathbf{h}\right)\end{array}$ & Cooling & $\begin{array}{c}\text { Aging \#1 } \\
\left({ }^{\circ} \mathbf{C} / \mathbf{h}\right)\end{array}$ & $\begin{array}{c}\text { Cooling rate } \\
\text { to reach } \\
\text { aging \#2 } \\
\left({ }^{\circ} \mathbf{C} / \mathbf{h}\right)\end{array}$ & $\begin{array}{c}\text { Aging \#2 } \\
\left({ }^{\circ} \mathbf{C} / \mathbf{h}\right)\end{array}$ & $\begin{array}{c}\text { Cooling } \\
\text { rate to } \\
\text { room } \\
\text { temp. }\end{array}$ \\
\hline W718-Z1653 & $1174 / 2+1204 / 6$ & $\mathrm{WC}$ & $1093 / 1$ & $\mathrm{AC}$ & $718 / 8$ & 55 & $621 / 8$ & $\mathrm{AC}$ \\
\hline $\mathrm{AM} 718-\mathrm{HT} 1$ & $1174 / 2+1204 / 6$ & $\mathrm{WC}$ & $945 / 1$ & $\mathrm{AC}$ & $718 / 8$ & 55 & $621 / 8$ & $\mathrm{AC}$ \\
\hline $\mathrm{AM} 718-\mathrm{HT} 2$ & $1174 / 2+1204 / 6$ & $\mathrm{WC}$ & $1093 / 1$ & $\mathrm{AC}$ & $718 / 8$ & 55 & $621 / 8$ & $\mathrm{AC}$ \\
\hline $\mathrm{AM} 718-\mathrm{HM}$ & $1174 / 2+1204 / 6$ & $\mathrm{WC}$ & $1093 / 1$ & $\mathrm{AC}$ & $\mathrm{N} / \mathrm{A}$ & $\mathrm{N} / \mathrm{A}$ & $\mathrm{N} / \mathrm{A}$ & $\mathrm{N} / \mathrm{A}$ \\
\hline
\end{tabular}




\section{MICROSTRUCTURE CHARACTERIZATION}

TEM lamella were prepared on either an FEI Versa Nanolab 650 or an FEI Quanta Nanolab focused ion beam (FIB) system at the Low Activation Materials and Development Analysis (LAMDA) laboratory at ORNL by using standardized lift-out procedures. Each lamella was made with a thick window frame to prevent foil bending and twisting during sample thinning below a thickness of $\sim 300 \mathrm{~nm}$. A low-energy Ga ion beam ( 2 and $5 \mathrm{keV}$ ) was used to thin the $\sim 150 \mathrm{~nm}$ thick lamella to a final thickness of around 80 $100 \mathrm{~nm}$, which effectively eliminated the TEM-visible FIB damage induced at high-beam energy.

The microstructure for each heat treatment of AM718 and W718 was characterized by using the FEI Talos F200X scanning transmission electron microscope (STEM) instrument equipped with high counting rate EDS in LAMDA [33]. Before imaging and EDS spectra collection, the lamella was tilted to a low order zone axis, such as the (001), and the collection angles optimized. STEM images were collected across four detectors: a bright field detector, two concentric dark field detectors (DF1 and DF2), and a high angle annular dark field (HAADF) detector. Each STEM image was collected with a region of interest size of 2,048 $\times 2,048$ pixels with a resolution of $\sim 0.7 \mathrm{~nm} /$ pixel. Additional images were collected as needed at a higher resolution of $0.16 \mathrm{~nm} /$ pixel to confirm the precipitate structure and composition. EDS-based spectrum images for precipitate measurement were taken over a broad area by using a regionof-interest size of $1,024 \times 1,024$ pixels with a resolution of $\sim 1.3 \mathrm{~nm} /$ pixel, a probe full-width halfmaximum of $\sim 1.5 \mathrm{~nm}$, and a beam current of around 3nA. Each scan had a duration of $1 \mathrm{~h}$ with more than 35,000 counts/s and dead times from 1-6\%. The qualitative x-ray counts were converted to quantified weight percentages by using the Cliff-Lorimer [34] method for calculation at each pixel.

Each corresponding collection of STEM images and EDS spectrum images was characterized for nanoscale features. Precipitates were identified by using the composition expected for each phase [7] and overlaying the corresponding EDS maps for the elements of interest in the phase. Each feature was annotated by using hand counting procedures and designated as belonging to a class. These annotations were used to produce an image in which the type of feature present at any given pixel was labeled by a class number. Each feature class was individually filtered out of the image and analyzed by using the particle analysis function in FIJI [35] to obtain parameters for the area, perimeter, minimum width, maximum width, and circularity for each feature present. An equivalent diameter for each feature to use with the dispersed barrier hardening model was calculated using Eq. (4). The mean and standard error of the mean for the equivalent diameter were calculated for each identified feature of the microstructure.

$$
d_{e q}=\sqrt{\text { major axis } \times \text { minor axis. }} .
$$

\subsection{RESULTS OF MICROSTRUCTURE CHARACTERIZATION}

The first characterization performed was on the ASB 3D printed Inconel 718. An overview of the microstructure at the micron scale is shown in Figure 3 in which the print direction is out of the page. The grain structure consisted of fine lath-like boundaries decorated with $\mathrm{Nb}$-rich precipitates. Toward the part exterior, the Laves phase formed as a dendrite, and the $\delta$ phase formed on boundaries nearer the part interior. As both phases compete for $\mathrm{Nb}$ in the alloy, the distribution of each phase is likely controlled by the kinetics during fabrication and solidification [36]. For volumes of the part consistently above the $\delta$ solvus line at $1,010^{\circ} \mathrm{C}[37,38]$, Laves phase formation is preferred as a metastable phase from solidification, whereas the $\delta$ phase forms latter in the fabrication process. During the casting and forging process, wrought Inconel 718 is homogenized to solution of the Laves phase that leads to the formation of other $\mathrm{Nb}$-containing phases. At a higher magnification, a high density of $\gamma^{\prime \prime}$ precipitates were observed in the vicinity of larger $\delta$ phase particles (Figure 4 ), which is consistent with previous observations from AM-fabricated Inconel 718 [39] and as-cast wrought Inconel 718 [38]. The time-temperature- 
precipitation diagram suggests that at higher temperatures, such as those present during AM, the formation of interdendritic $\gamma^{\prime \prime}$ was favored over $\gamma^{\prime \prime}$ interior to the grain [39]. Interspersed throughout the grain interiors was a mixture of fine $\gamma^{\prime}$ and $\gamma^{\prime \prime}$ precipitates with a very high density (Figure 5) with the frequency size distributions in Figure 6. Two nonoverlapping areas were examined for precipitate formation closer to the part interior to attempt to capture representative microstructures. A quantitative summary of the microstructure is included in Table 3 that contains the number of precipitates observed, the percentage that each precipitate phase contributes to the total precipitation, the mean equivalent diameter, the standard error of the mean equivalent diameter, and the number density for each phase. Between the two areas examined, the size and density of $\gamma^{\prime \prime}$, Laves, and oxide precipitates were found to be nearly identical. However, both $\gamma^{\prime}$ and $\delta$ showed a large variation in density $(\sim 2 \times)$ between ASB-1 and ASB-2 with no carbides being observed in ASB-2. Although mechanical properties could be obtained for comparison with this microstructure, it is unlikely to yield correlative results because of the high level of complexity and heterogeneity found in the ASB Inconel 718. Therefore, ASB Inconel 718 was excluded from the mechanical testing campaign during FY21.

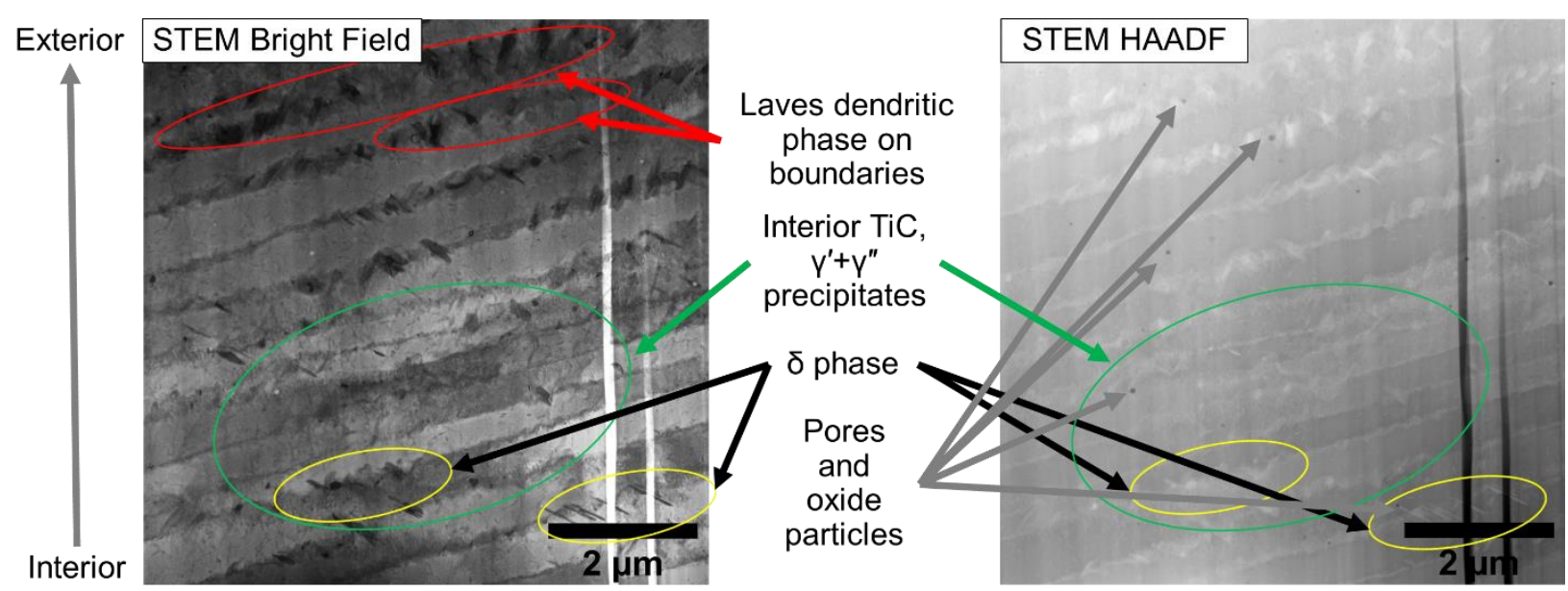

Figure 3. STEM images of ASB AM Inconel 718 showing dendritic Laves phase, large $\delta$ precipitates, TiC, pores, oxide particles, and $\gamma^{\prime}$ and $\gamma^{\prime \prime}$ precipitates. 


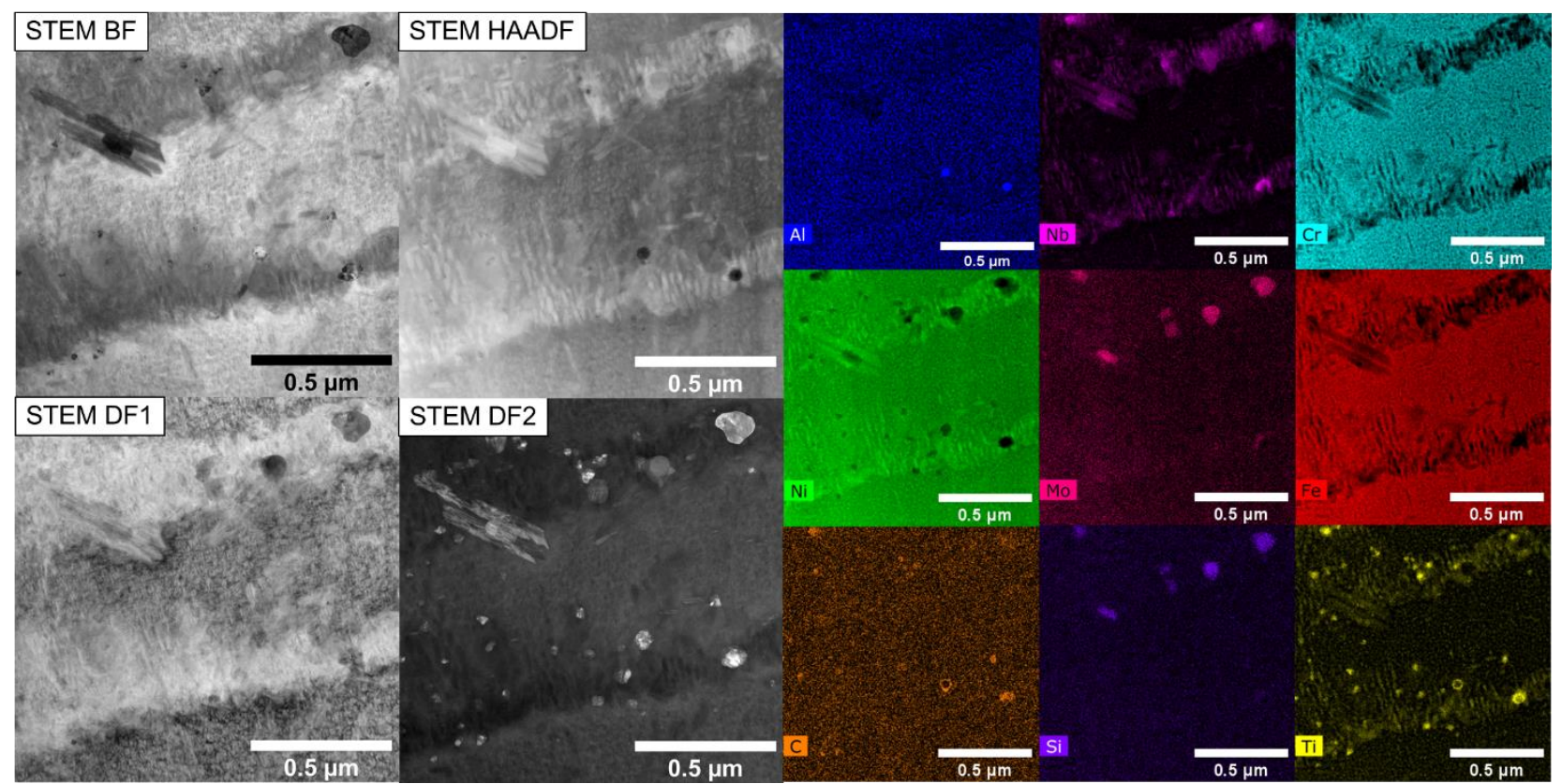

Figure 4. STEM images of ASB AM Inconel 718 with corresponding EDS maps for precipitate-forming elements showing large $\delta$ precipitates $\left(\mathrm{Ni}_{3} \mathrm{Nb}\right)$, Laves particles ( $\mathrm{Nb}-\mathrm{Mo}-\mathrm{Si}$ rich), TiC, and $\gamma^{\prime \prime}$ precipitates $\left(\mathrm{Ni}{ }_{3} \mathrm{Nb}\right)$.

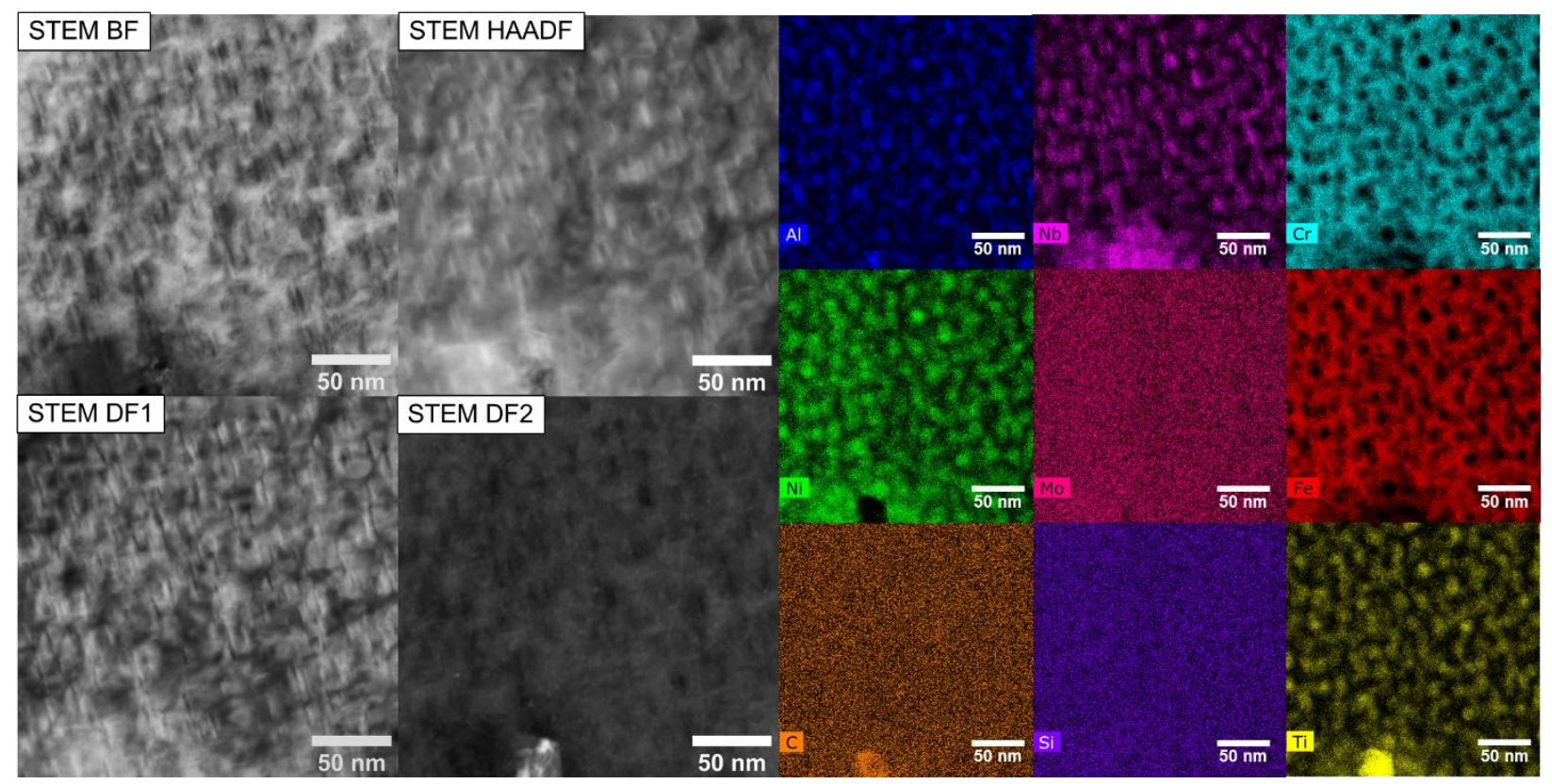

Figure 5. Higher magnification STEM images of ASB AM Inconel 718 with corresponding EDS maps for precipitate forming elements showing $\gamma^{\prime}\left(\mathrm{Ni}_{3}(\mathrm{Ti}, \mathrm{AI})\right)$ and $\gamma^{\prime \prime}\left(\mathrm{Ni}_{3} \mathrm{Nb}\right)$ precipitates. 
Table 3. Summary of characterization results for precipitate phases observed in ASB AM718. The error in number densities is the minimum of error from counting statistics [40] or from the TEM foil thickness measurement. N.O. indicates that the feature was not observed.

\begin{tabular}{|c|c|c|c|c|c|c|}
\hline $\begin{array}{c}\text { Alloy } \\
\text { designation }\end{array}$ & Feature & $\begin{array}{c}\text { Number of } \\
\text { features } \\
\text { observed }\end{array}$ & $\begin{array}{c}\text { Percent of } \\
\text { total } \\
\text { precipitation } \\
(\mathbf{\%})\end{array}$ & $\begin{array}{c}\text { Mean eq. } \\
\text { diameter } \\
(\mathbf{n m})\end{array}$ & $\begin{array}{c}\text { Standard } \\
\text { error of mean } \\
(\mathbf{n m})\end{array}$ & $\begin{array}{c}\text { Number density } \\
\left(\mathbf{m}^{-3}\right)\end{array}$ \\
\hline \multirow{4}{*}{$\begin{array}{c}\text { AM718- } \\
\text { ASB-1 }\end{array}$} & $\gamma^{\prime}$ & 571 & 16.08 & 8.34 & 0.11 & $2.68 \pm 0.3 \times 10^{21}$ \\
\cline { 2 - 7 } & $\gamma^{\prime \prime}$ & 2,484 & 69.94 & 9.47 & 0.14 & $1.17 \pm 0.1 \times 10^{22}$ \\
\cline { 2 - 7 } & Laves & 467 & 13.15 & 9.89 & 0.55 & $2.19 \pm 0.2 \times 10^{21}$ \\
\cline { 2 - 7 } & Carbides & 7 & 0.20 & 77.25 & 9.9 & $3.29 \pm 0.6 \times 10^{19}$ \\
\cline { 2 - 7 } & Cavities & 15 & 0.42 & 27.52 & 2.7 & $7.04 \pm 0.9 \times 10^{19}$ \\
\cline { 2 - 7 } & Oxide & 7 & - & 12.49 & 1.3 & $4.70 \pm 0.8 \times 10^{19}$ \\
\hline \multirow{4}{*}{$\begin{array}{c}\text { AM718- } \\
\text { ASB-2 }\end{array}$} & $\gamma^{\prime}$ & 247 & 8.27 & 10.59 & 0.21 & $1.16 \pm 0.2 \times 10^{21}$ \\
\cline { 2 - 7 } & $\gamma^{\prime \prime}$ & 2,570 & 86.01 & 10.05 & 0.09 & $1.21 \pm 0.1 \times 10^{22}$ \\
\cline { 2 - 7 } & Laves & 156 & 5.22 & 14.34 & 1.9 & $7.33 \pm 0.9 \times 10^{20}$ \\
\cline { 2 - 7 } & Carbides & 9 & 0.30 & 51.56 & 14.9 & $4.23 \pm 0.4 \times 10^{19}$ \\
\cline { 2 - 7 } & Cavities & 26 & - & - & - & - \\
\cline { 2 - 7 } & Oxide & 7 & 0.20 & 14.3 & 6.7 & $2.82 \pm 0.6 \times 10^{19}$ \\
\hline
\end{tabular}
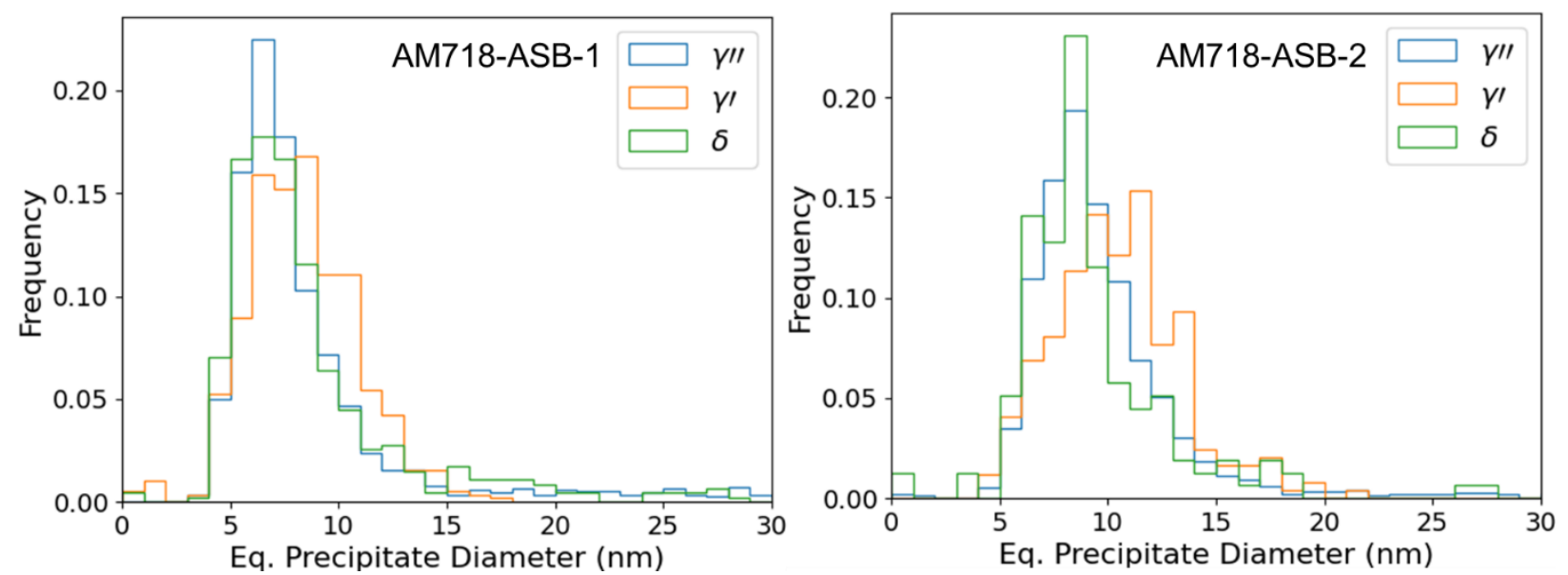

Figure 6. Precipitate size distributions for $\gamma^{\prime}, \gamma^{\prime \prime}$, and $\delta$ phases in ASB AM Inconel 718.

The microstructure found in the heat-treated specimens was not as complex as the ASB AM718.

Representative STEM HAADF images for the wrought Inconel 718 and the three heat treatments of AM718 are shown in Figure 7. The wrought alloy contained the expected microstructure that consists of a high density of fine $\gamma^{\prime}$ and $\gamma^{\prime \prime}$ precipitates consistent with the ASTM-prescribed microstructure for precipitate-hardened superalloys [30]. Following the homogenization treatment to produce AM718-HM, the microstructure consisted of a low density of remaining oxide and carbide particles and dissolved all Laves, $\delta, \gamma^{\prime}$, or $\gamma^{\prime \prime}$ phases present in the ASB AM718. After aging, the AM718-HT1 and AM718-HT2 treatments appeared qualitatively similar and contained a high density of fine $\gamma^{\prime}, \gamma^{\prime \prime}$, and $\delta$ precipitates with AM718-HT2 having greater precipitate densities overall. However, AM718-HT1 contained a higher 
fraction of $\delta$ phase, as expected from the heat treatment. The quantitative analysis of $\gamma^{\prime}, \gamma^{\prime \prime}$, and $\delta$ particles is provided in Table 4 with the size distribution of $\gamma^{\prime}, \gamma^{\prime \prime}$, and $\delta$ precipitates from each heat treatment shown in Figure 8.

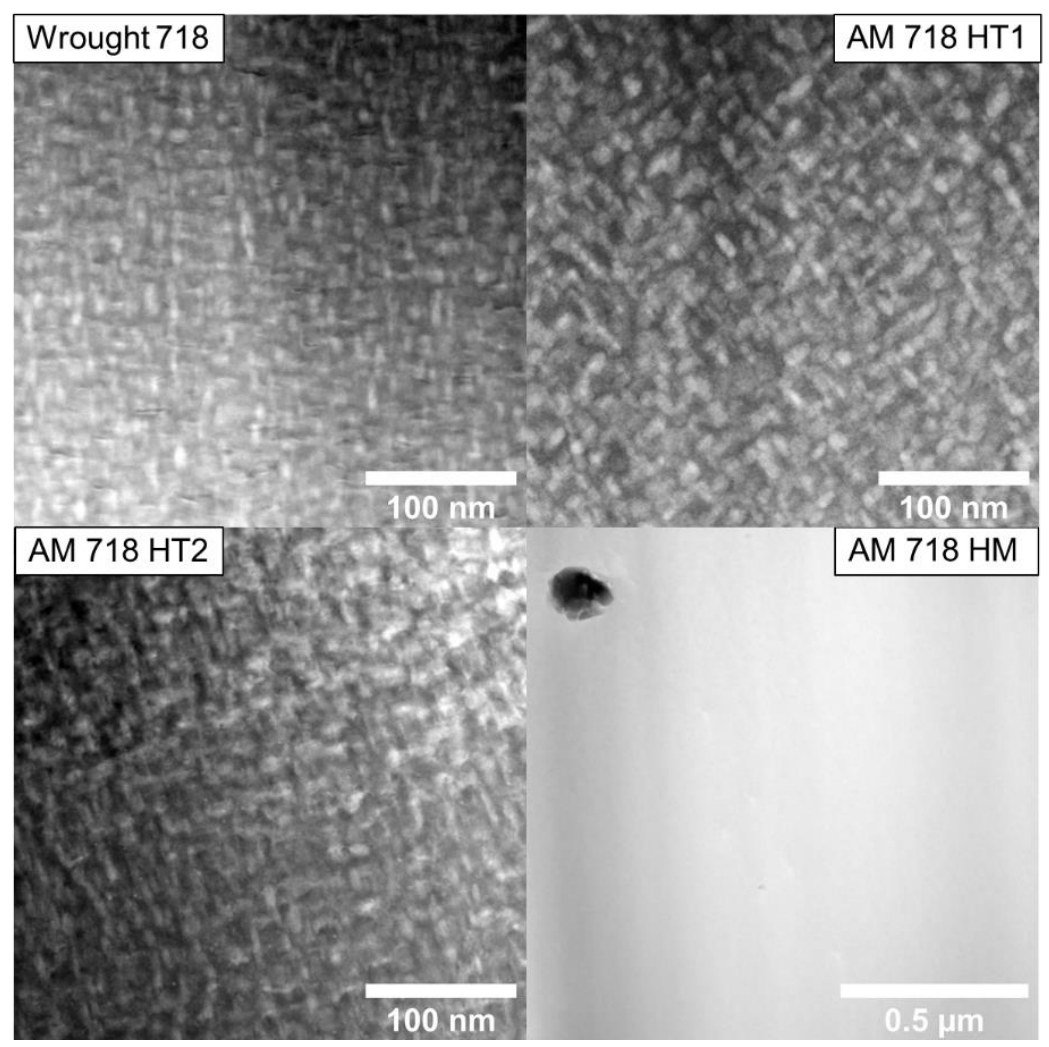

Figure 7. STEM HAADF images of wrought Inconel 718, AM718-HT1, AM718-HT2, and AM718-HM showing the mixture of $\gamma^{\prime}, \gamma^{\prime \prime}$, and $\delta$ as bright features and oxides as dark features. 
Table 4. Summary of characterization results for precipitate phases observed in heat-treated AM718. The error in number densities is the minimum of error from counting statistics [40] or from the TEM foil thickness measurement. N.O. indicates that the feature was not observed. N/A indicates there was not enough of

the feature to calculate this value.

\begin{tabular}{|c|c|c|c|c|c|c|}
\hline $\begin{array}{c}\text { Alloy } \\
\text { designation }\end{array}$ & Feature & $\begin{array}{l}\text { Number of } \\
\text { features } \\
\text { observed }\end{array}$ & $\begin{array}{c}\text { Percent of } \\
\text { total } \\
\text { precipitation } \\
(\%)\end{array}$ & $\begin{array}{l}\text { Mean eq. } \\
\text { diameter } \\
(\mathbf{n m})\end{array}$ & $\begin{array}{l}\text { Standard } \\
\text { error of mean } \\
\quad(\mathbf{n m})\end{array}$ & $\begin{array}{l}\text { Number density } \\
\qquad\left(\mathbf{m}^{-3}\right)\end{array}$ \\
\hline \multirow{7}{*}{ AM718-HT1 } & $\gamma^{\prime}$ & 407 & 7.39 & 8.16 & 0.09 & $1.91 \pm 0.2 \times 10^{21}$ \\
\hline & $\gamma^{\prime \prime}$ & 4,615 & 83.74 & 8.93 & 0.04 & $2.17 \pm 0.2 \times 10^{22}$ \\
\hline & $\delta$ & 487 & 8.84 & 8.17 & 0.08 & $2.29 \pm 0.2 \times 10^{21}$ \\
\hline & Laves & N.O. & - & - & - & - \\
\hline & Carbides & 2 & 0.04 & 35.2 & 14.4 & $9.39 \pm 1.2 \times 10^{18}$ \\
\hline & Cavities & N.O. & - & - & - & - \\
\hline & Oxide & N.O. & - & - & - & - \\
\hline \multirow{7}{*}{ AM718-HT2 } & $\gamma^{\prime}$ & 846 & 9.93 & 6.80 & 0.073 & $3.97 \pm 0.4 \times 10^{21}$ \\
\hline & $\gamma^{\prime \prime}$ & 7,208 & 84.59 & 7.72 & 0.024 & $3.39 \pm 0.3 \times 10^{22}$ \\
\hline & $\delta$ & 466 & 5.47 & 7.06 & 0.062 & $2.19 \pm 0.2 \times 10^{21}$ \\
\hline & Laves & N.O. & - & - & - & - \\
\hline & Carbides & 1 & 0.01 & 63.59 & N/A & $4.70 \pm 2.4 \times 10^{18}$ \\
\hline & Cavities & N.O. & - & - & - & - \\
\hline & Oxide & N.O. & - & - & - & - \\
\hline \multirow{7}{*}{$\begin{array}{c}\text { AM718-HM- } \\
1\end{array}$} & $\gamma^{\prime}$ & N.O. & - & - & - & - \\
\hline & $\gamma^{\prime \prime}$ & N.O. & - & - & - & - \\
\hline & $\delta$ & N.O. & - & - & - & - \\
\hline & Laves & N.O. & - & - & - & - \\
\hline & Carbides & 3 & 75.00 & 45.79 & 13.7 & $1.41 \pm 0.5 \times 10^{19}$ \\
\hline & Cavities & N.O. & - & - & - & - \\
\hline & Oxide & 1 & 25.00 & 135.89 & N/A & $4.70 \pm 2.4 \times 10^{18}$ \\
\hline \multirow{7}{*}{$\begin{array}{c}\text { AM718-HM- } \\
2\end{array}$} & $\gamma^{\prime}$ & N.O. & - & - & - & - \\
\hline & $\gamma^{\prime \prime}$ & N.O. & - & - & - & - \\
\hline & $\delta$ & N.O. & - & - & - & - \\
\hline & Laves & N.O. & - & - & - & - \\
\hline & Carbides & 4 & 66.67 & 81.83 & 49.5 & $1.88 \pm 0.6 \times 10^{19}$ \\
\hline & Cavities & 1 & - & 11.10 & N/A & $4.70 \pm 2.4 \times 10^{18}$ \\
\hline & Oxide & 2 & 33.33 & 47.33 & 40.9 & $9.39 \pm 1.8 \times 10^{18}$ \\
\hline
\end{tabular}



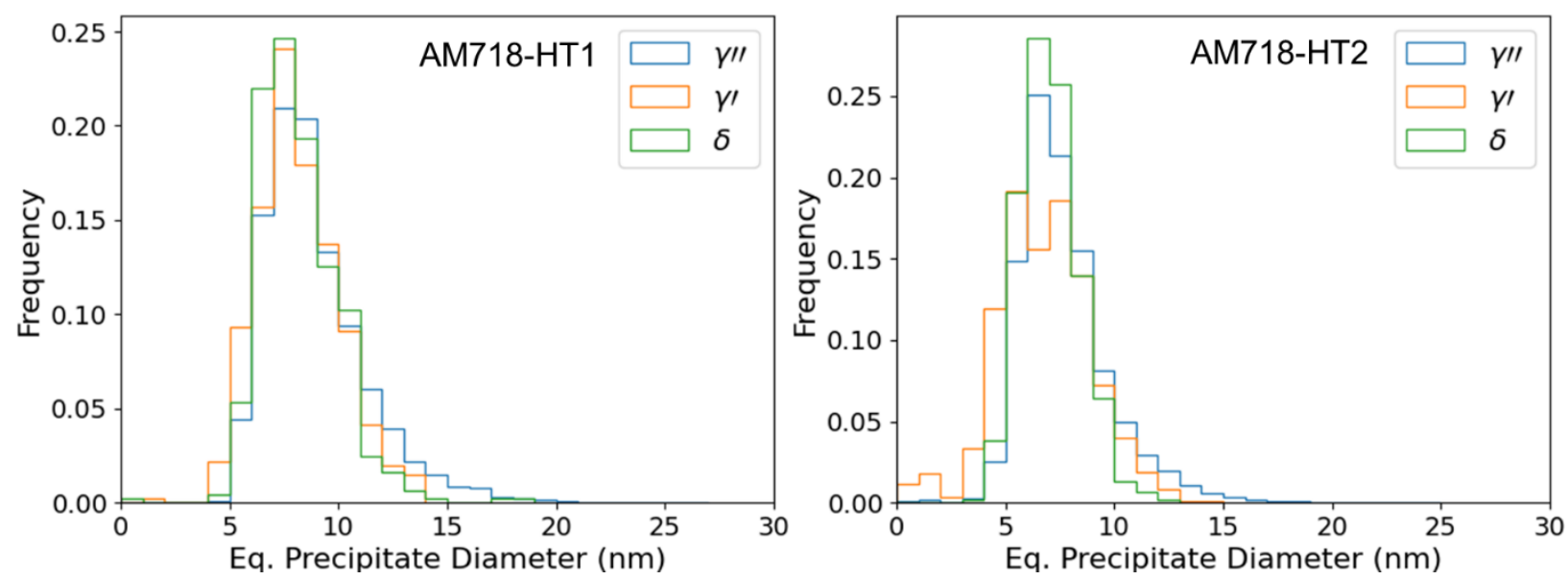

Figure 8. Precipitate size distributions for $\gamma^{\prime}, \gamma^{\prime \prime}$, and $\delta$ phases in heat-treated AM Inconel 718.

\section{BASELINE MECHANICAL PROPERTIES}

SS-J2 specimens were tested for baseline mechanical properties by using uniaxial tensile straining. Room temperature tensile straining was conducted according to ASTM E8/E8M and ASTM E21-20 for elevated temperatures. The straining was maintained at a crosshead displacement of $0.15 \mathrm{~mm} / \mathrm{min}$ for a strain rate of $5 \times 10^{-4} \mathrm{~s}^{-1}$ to avoid complications typical at high strain rates [41]. Specimens were strained to failure at the test temperature, as shown in Table 5.

Table 5. Tensile tests conducted in FY21 of AM718 and W718 at room temperature and elevated temperatures.

\begin{tabular}{|c|c|c|c|c|}
\hline \multirow{2}{*}{ Alloy designation } & \multicolumn{3}{|c|}{ Number of specimens tested at each temperature } \\
\cline { 2 - 5 } & Room temperature & $\mathbf{3 0 0}^{\circ} \mathbf{C}$ & $\mathbf{4 5 0}^{\circ} \mathbf{C}$ & $\mathbf{6 0 0}^{\circ} \mathbf{C}$ \\
\hline W718 & 5 & 5 & 5 & 5 \\
\hline AM718-HT1 & 5 & 5 & 5 & 5 \\
\hline AM718-HT2 & 5 & 5 & 5 & 5 \\
\hline AM718-HM & 5 & 5 & 5 & 5 \\
\hline
\end{tabular}

This report was limited to room temperature tensile properties because it is the most common data available in literature. Representative engineering stress-strain curves for each heat treatment of AM718 and the reference wrought alloy 718, labeled as W718, strained at room temperature are shown in Figure 9. Engineering stress-strain curves for each strained specimen from each condition are displayed in Figure 10. From these curves, the common engineering properties of elastic modulus, $0.2 \%$ offset yield strength, uniform elongation, ultimate tensile stress, fracture strain, and fracture stress were calculated and included in Table 6. 


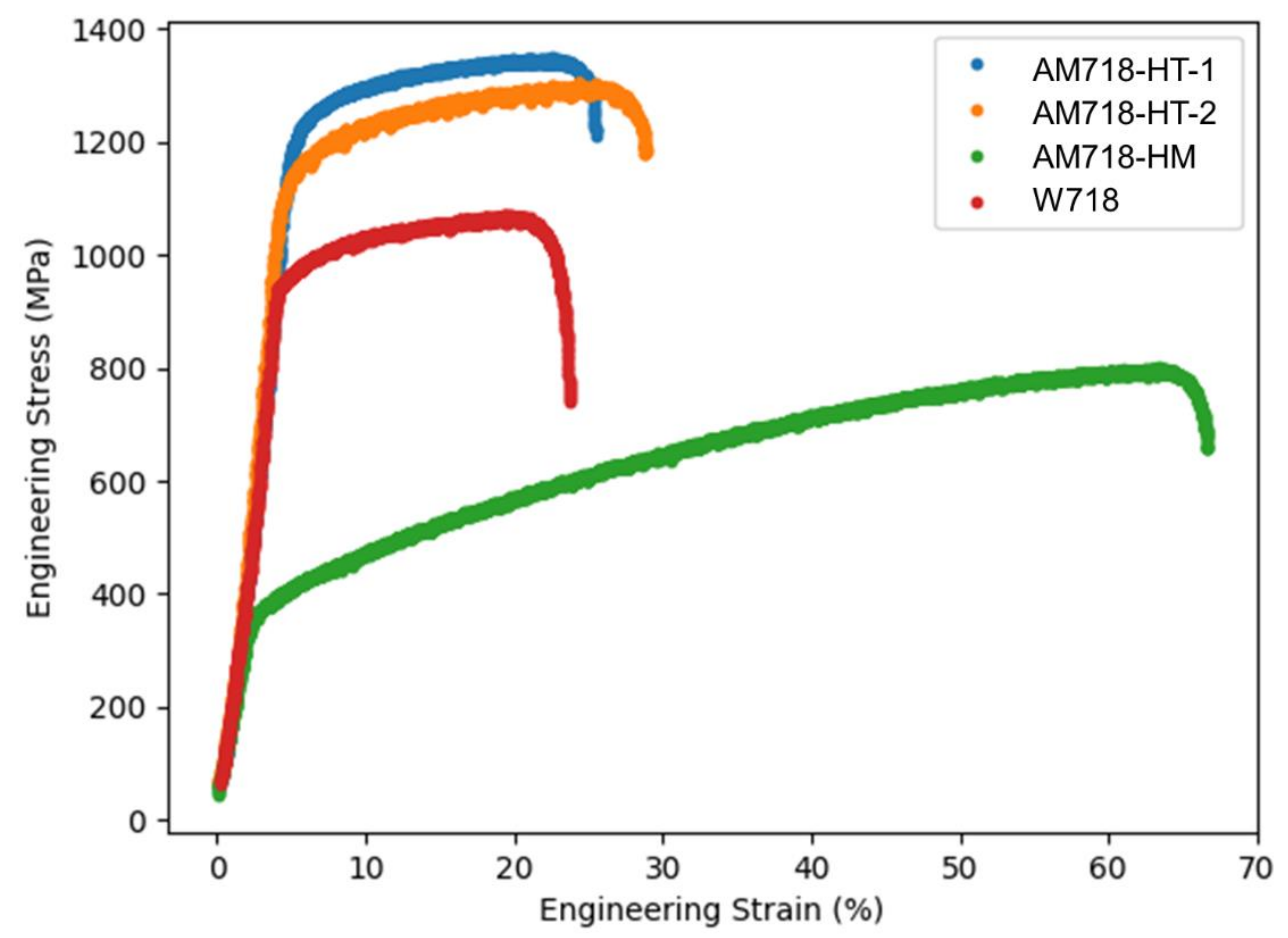

Figure 9. Representative engineering stress-strain curves for heat-treated AM Inconel 718 and wrought Inconel 718 at room temperature. 


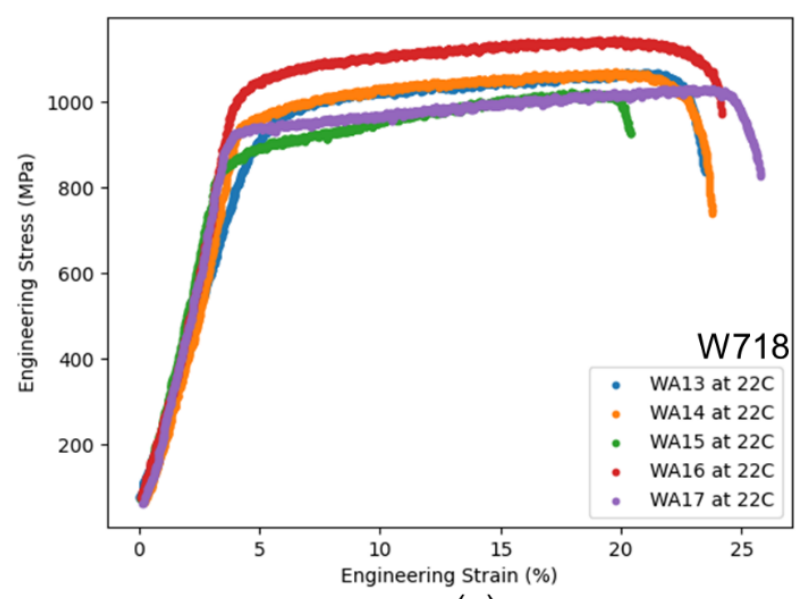

(a)

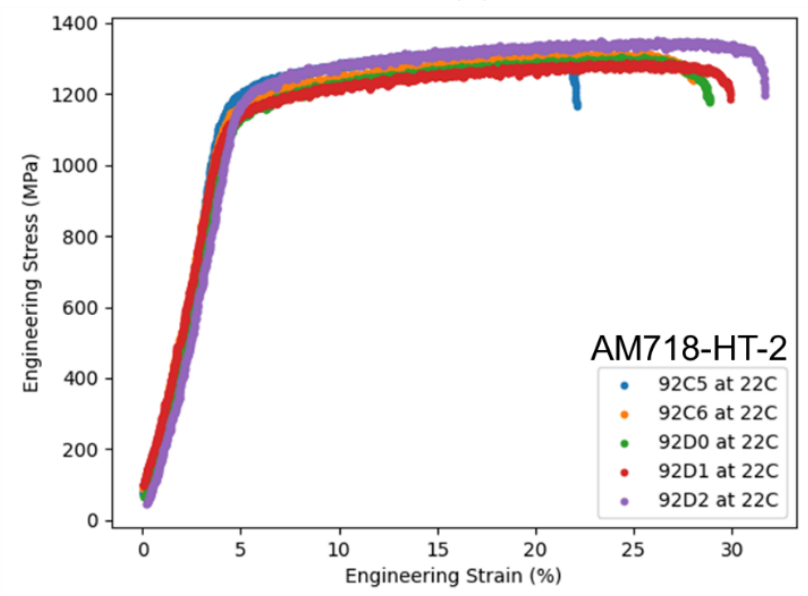

(c)

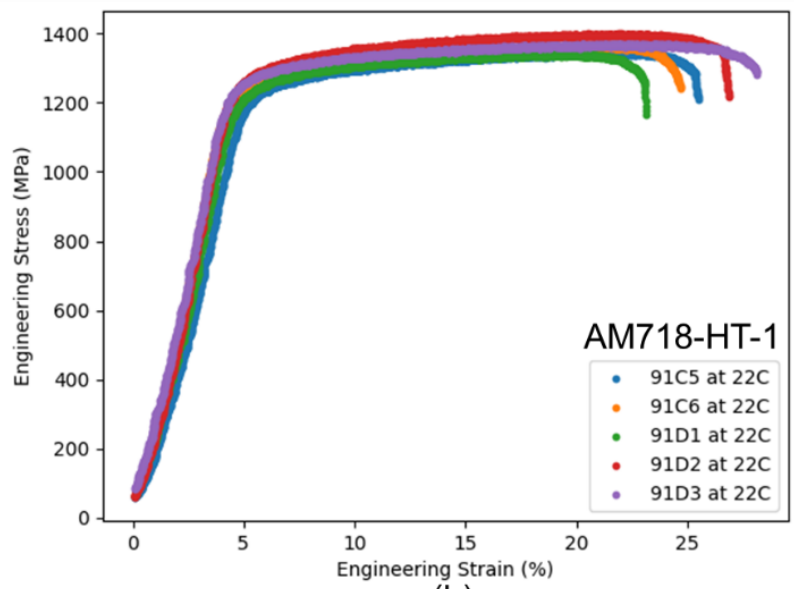

(b)

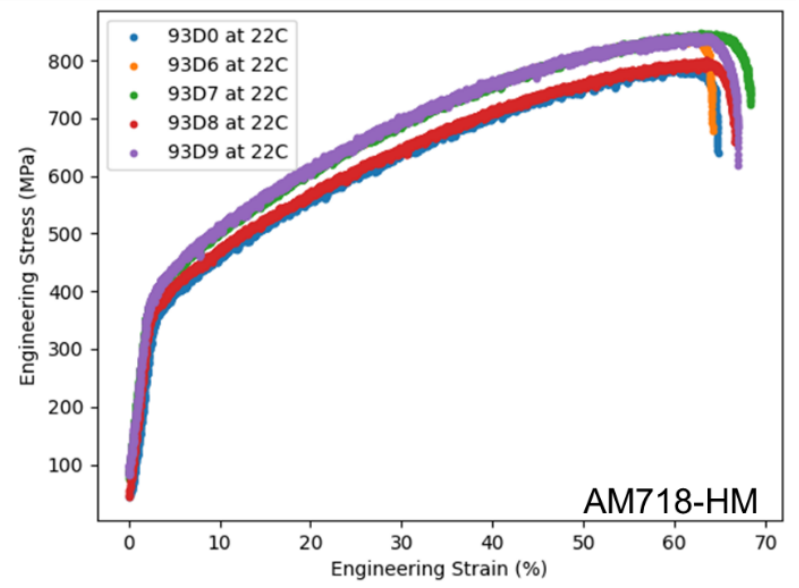

(d)

Figure 10. Individual engineering stress-strain curves for wrought Inconel 718 (a) and heat-treated AM Inconel 718 (b-d) at room temperature.

Table 6. Engineering properties derived from room temperature tensile tests conducted in FY21 of wrought Inconel 718 and heat-treated AM Inconel 718. Values reported are the average of all tested specimens and associated standard deviation.

\begin{tabular}{|l|c|c|c|c|c|c|c|}
\hline Designation & $\begin{array}{c}\text { Test } \\
\text { temp. } \\
\left({ }^{\circ} \mathbf{C}\right)\end{array}$ & $\begin{array}{c}\text { Elastic } \\
\text { modulus } \\
(\mathbf{G P a})\end{array}$ & $\begin{array}{c}\mathbf{0 . 2 \%} \text { offset } \\
\text { yield } \\
(\mathbf{M P a})\end{array}$ & $\begin{array}{c}\text { Uniform } \\
\text { elongation } \\
(\mathbf{\%})\end{array}$ & $\begin{array}{c}\text { Ultimate } \\
\text { tensile } \\
\text { strength } \\
(\mathbf{M P a})\end{array}$ & $\begin{array}{c}\text { Fracture } \\
\text { strain } \\
(\boldsymbol{\%})\end{array}$ & $\begin{array}{c}\text { Fracture } \\
\text { stress } \\
(\mathbf{M P a})\end{array}$ \\
\hline W718-Z1653 & 22 & $213 \pm 2.3$ & $772 \pm 95.5$ & $14.9 \pm 1.8$ & $1,067 \pm 42.8$ & $19.7 \pm 2.1$ & $844.9 \pm 89.3$ \\
\hline AM718-HT1 & 22 & $244 \pm 1.9$ & $806 \pm 59.6$ & $14.6 \pm 1.9$ & $1,365 \pm 20.3$ & $21.2 \pm 2.1$ & $1,158 \pm 51.7$ \\
\hline AM718-HT2 & 22 & $234 \pm 1.2$ & $788 \pm 65.7$ & $18.5 \pm 2.7$ & $1,316 \pm 21.4$ & $23.5 \pm 3.3$ & $1,159 \pm 28.0$ \\
\hline AM718-HM & 22 & $131 \pm 6.1$ & $389 \pm 17.0$ & $54.1 \pm 1.2$ & $824 \pm 23.4$ & $66.7 \pm 1.7$ & $635 \pm 30.0$ \\
\hline
\end{tabular}

The wrought Inconel 718 displayed the expected behavior for a precipitate-hardened alloy consisting of a large yield stress and high ultimate tensile stress. However, both the yield and ultimate tensile stress were 15-20\% lower than expected for the ASTM heat treatment $[8,42]$ and had an increased uniform elongation and fracture strain compared with literature $[8,38,43]$. The combination of these observations suggests one of two possibilities. The first possibility is that the heat treatment did not nucleate all the 
possible $\gamma^{\prime \prime}$ precipitates that could form from the $\mathrm{Nb}$ content in the wrought Inconel 718, requiring further aging to complete precipitation. The second possibility is that a fraction of the metastable $\gamma^{\prime \prime}$ transformed into $\delta$-phase precipitates as predicted by the time-temperature-transformation diagram [37]. Although $\delta$ precipitates shares the composition of $\mathrm{Ni}_{3} \mathrm{Nb}$ with $\gamma^{\prime \prime}$, the lattice-precipitate interface is incoherent for the $\delta$-phase, reducing its contribution to the strength [8]. Quantitative microstructural characterization of the wrought alloy 718 is in progress to determine the size and density of precipitating phases.

Following similar heat treatments to the ASTM treatment as done with AM718-HT1 and AM718-HT2 ( Table 2), the yield strength and ultimate tensile strength increased relative to W718 and well within ASTM specifications of Inconel 718 [42]. The AM718-HT2 condition displayed many uniform elongations after yield compared with AM718-HT1. Comparing the microstructures of these two conditions from Table 4, both exhibited a high density of $\gamma^{\prime \prime}$ precipitates on the order of $10^{22} \mathrm{~m}^{-3}$ with AM718-HT-2 having a larger density. However, AM718-HT1 had a higher fraction of the $\delta$-phase, which likely contributed to the decrease in uniform elongation. The agreement in the uniform elongation between AM718-HT-1 and W718 lends support to the aforementioned hypothesis regarding the formation of $\delta$-phase precipitates in W718.

When the precipitates were removed through homogenization and solution annealing (AM718-HM), the yield stress and ultimate tensile strength decreased with a significantly larger uniform elongation and fracture strain consistent with solution-annealed Inconel 718 [44]. However, the elastic modulus was significantly lower than the 190-220 GPa range expected for polycrystalline Ni [45]. In the literature, a decreased elastic modulus was found when annealing at high temperatures for $1 \mathrm{~h}$ to achieve values of 165-172 GPa [46-51]. Increasing the annealing temperature reduced the elastic modulus linearly and correlated with an increase in the grain size [48]. Compared with these previous works, the homogenization treatment was performed for a much longer time, and thus this condition likely experienced grain growth. The solid solution of $\mathrm{Nb}$ in the FCC Ni lattice might also contribute to this observation because solute additions of $\mathrm{Cu}$ have generated local minima in the elastic properties [46, 48]. Investigations to determine the grain size and effect of $\mathrm{Nb}$ in a solid solution are ongoing.

\section{SUMMARY AND CONCLUSIONS}

Microstructure characterization and baseline mechanical testing were performed on additively manufactured Inconel 718 produced via LPBF. This discussion focuses on the correlations between the microstructure of the heat-treated Inconel 718 and the corresponding tensile properties. The key findings and conclusions derived from this work are summarized as follows.

1. The microstructure of ASB Inconel 718 contained many of the phases predicted from the isothermal phase diagram with strong variation, depending on where in the part was examined at the nano- to micro-scales. The inherent complexity of the ASB Inconel 718 would muddle the interpretation of any mechanical properties, so it was excluded from the mechanical testing campaign.

2. Three heat treatments were employed to control the precipitate morphology in additively manufactured Inconel 718 after fabrication. Microstructure homogenization led to a highly ductile Inconel with lower strength compared with wrought Inconel 718. The tensile properties of additively manufactured 718 that use a standard ASTM-recommended heat treatment were consistent with the literature. A higher fraction of the $\delta$ phase in AM718-HT1 led to shorter uniform elongation with all other engineering properties being equivalent to AM718-HT2. 


\section{FUTURE WORK}

Although several engineering properties were determined by using the approach and methods described in this report, there are still several areas in which this work is expected to grow. The microstructure and properties were determined for the three simpler heat treatments of AM Inconel 718, and properties for the ASB AM Inconel 718 were not collected because of the lack of in situ monitoring during the build process. One strong goal of the TCR program is to not only link the fabrication parameters with the resulting properties but to also use the data recorded during fabrication to predict and qualify a component. Therefore, future work to collect the properties of AM-produced Inconel 718 will be pursued when an in situ database is available on the Concept X-Line 2000R at the MDF. This capability is expected to be available in FY22. Baseline mechanical properties and a qualitative interpretation of the microstructure for a wrought Inconel 718 were included in this report, and quantitative microstructure characterization will be completed in late FY21.

\subsection{NEUTRON IRRADIATION PLAN AND PIE}

Because of the lack of irradiation data on the precipitates and mechanical properties of Ni superalloys, the TCR program developed a neutron irradiation plan using HFIR to investigate the TCR's response to the combined environment of high temperatures and radiation damage. The irradiation test matrix, shown in Table 7, comprised two temperatures, representing the bounds of the TCR operating conditions, and two cycle durations to explore low neutron doses and a dose exceeding the planned operation of TCR. Given the inherent complexity in the ASB superalloy 718, the wrought alloy 718 and the three heat treatments of AM 718 were chosen for studying irradiation effects on the microstructure and mechanical properties. The capsules were built according to the general tensile capsule design to accommodate subsize specimens [32]. The capsules that contained these specimens were inserted in May 2021. The first set of capsules was removed in June 2021. The second set will be removed in FY22. Post irradiation examination of Inconel 718 for mechanical properties and irradiated microstructure characterization is a planned activity for the TCR program in FY22. An aging effect study on the Inconel 718 alloy samples will be also performed in the same period.

Table 7. HFIR irradiation conditions for Inconel 718 as part of TCR.

\begin{tabular}{|c|c|c|c|c|}
\hline Capsule type & Samples included & $\begin{array}{c}\text { Samples per } \\
\text { capsule }\end{array}$ & $\begin{array}{c}\text { Number of HFIR } \\
\text { cycles }\end{array}$ & $\begin{array}{c}\text { Target temperature } \\
\left({ }^{\circ} \mathbf{C}\right) \pm \mathbf{5 0} \mathbf{C}^{\circ}\end{array}$ \\
\hline \multirow{3}{*}{ SS-J2 Tensile } & $\begin{array}{c}\text { W718 } \\
\text { AM718-HT1 } \\
\text { AM718-HT2 } \\
\text { AM718-HM }\end{array}$ & 24 & 1 & 300 \\
\hline \multirow{5}{*}{ SS-J2 Tensile } & $\begin{array}{c}\text { W718 } \\
\text { AM718-HT1 } \\
\text { AM718-HT2 } \\
\text { AM718-HM }\end{array}$ & 24 & 5 & 300 \\
\hline \multirow{5}{*}{ SS-J2 Tensile } & $\begin{array}{c}\text { W718 } \\
\text { AM718-HT1 } \\
\text { AM718-HT2 } \\
\text { AM718-HM }\end{array}$ & 24 & 1 & 600 \\
\hline \multirow{5}{*}{ SS-J2 Tensile } & $\begin{array}{l}\text { W718 } \\
\text { AM718-HT1 } \\
\text { AM718-HT2 } \\
\text { AM718-HM }\end{array}$ & 24 & 5 & 600 \\
\hline
\end{tabular}




\section{REFERENCES}

[1] A.F. Rowcliffe, L.K. Mansur, D.T. Hoelzer, R.K. Nanstad, Perspectives on radiation effects in nickel-base alloys for applications in advanced reactors, J. Nucl. Mater. 392 (2009) 341-352. https://doi.org/10.1016/j.jnucmat.2009.03.023.

[2] H. Zhang, C. Li, Q. Guo, Z. Ma, H. Li, Y. Liu, Improving creep resistance of nickel-based superalloy Inconel 718 by tailoring gamma double prime variants, Scr. Mater. 164 (2019) 66-70. https://doi.org/10.1016/j.scriptamat.2019.01.041.

[3] C. Silva, M. Song, K. Leonard, M. Wang, G. Was, J. Busby, Characterization of alloy 718 subjected to different thermomechanical treatments, Mater. Sci. Eng. A. 691 (2017) 195-202. https://doi.org/10.1016/j.msea.2017.03.045.

[4] M. Griffiths, Ni-based alloys for reactor internals and steam generator applications, Elsevier Inc., 2019. https://doi.org/10.1016/B978-0-12-397046-6.00009-5.

[5] K.V.U. Praveen, G.V.S. Sastry, V. Singh, Work-hardening behavior of the Ni-Fe based superalloy IN718, Metall. Mater. Trans. A Phys. Metall. Mater. Sci. 39 (2008) 65-78. https://doi.org/10.1007/s11661-007-9375-3.

[6] H.S. Mali, D.R. Unune, Machinability of Nickel-Based Superalloys: An Overview, Elsevier Ltd., 2017. https://doi.org/10.1016/b978-0-12-803581-8.09817-9.

[7] C. Kumara, A.R. Balachandramurthi, S. Goel, F. Hanning, J. Moverare, Toward a better understanding of phase transformations in additive manufacturing of Alloy 718, Materialia. 13 (2020) 100862. https://doi.org/10.1016/j.mtla.2020.100862.

[8] D.D. Keiser, H.L. Brown, Review of the physical metallurgy of Alloy 718, U.S. Department of Energy, 1976. https://doi.org/10.2172/4016087.

[9] R.M. Boothby, The microstructure of fast neutron irradiated nimonic PE16, J. Nucl. Mater. 230 (1996) 148-157. https://doi.org/10.1016/0022-3115(96)00169-9.

[10] W.J.S. Yang, Grain boundary segregation in solution-treated Nimonic PE16 during neutron irradiation, J. Nucl. Mater. 108-109 (1982) 339-346. https://doi.org/10.1016/00223115(82)90503-7.

[11] M. Song, Y. Yang, M. Wang, W. Kuang, C.R. Lear, G.S. Was, Probing long-range ordering in nickel-base alloys with proton irradiation, Acta Mater. 156 (2018) 446-462.

https://doi.org/10.1016/j.actamat.2018.06.043.

[12] L.E. Thomas, B.H. Sencer, S.M. Bruemmer, Radiation-Induced Phase Instabilities and Their Effects on Hardening and Solute Segregation in Precipitation-Strengthened Alloy 718, in: Mater. Res. Soc. Symp. Proc., 2001: p. R1.5.1-R1.5.6.

[13] J.D. Hunn, E.H. Lee, T.S. Byun, L.K. Mansur, Ion-irradiation-induced hardening in Inconel 718, J. Nucl. Mater. 296 (2001) 203-209. https://doi.org/10.1016/S0022-3115(01)00519-0.

[14] F. Liu, F. Lyu, F. Liu, X. Lin, C. Huang, Laves phase control of inconel 718 superalloy fabricated by laser direct energy deposition via $\delta$ aging and solution treatment, J. Mater. Res. Technol. 9 (2020) 9753-9765. https://doi.org/10.1016/j.jmrt.2020.06.061.

[15] C. Zhong, J. Chen, S. Linnenbrink, A. Gasser, S. Sui, R. Poprawe, A comparative study of Inconel 718 formed by High Deposition Rate Laser Metal Deposition with GA powder and PREP powder, Mater. Des. 107 (2016) 386-392. https://doi.org/10.1016/j.matdes.2016.06.037. 
[16] D. Kong, C. Dong, X. Ni, L. Zhang, C. Man, J. Yao, Y. Ji, Y. Ying, K. Xiao, X. Cheng, X. Li, High-throughput fabrication of nickel-based alloys with different $\mathrm{Nb}$ contents via a dual-feed additive manufacturing system: Effect of $\mathrm{Nb}$ content on microstructural and mechanical properties, J. Alloys Compd. 785 (2019) 826-837. https://doi.org/10.1016/j.jallcom.2019.01.263.

[17] S. Sui, J. Chen, Z. Li, H. Li, X. Zhao, H. Tan, Investigation of dissolution behavior of laves phase in inconel 718 fabricated by laser directed energy deposition, Addit. Manuf. 32 (2020) 101055. https://doi.org/10.1016/j.addma.2020.101055.

[18] S. Sui, H. Tan, J. Chen, C. Zhong, Z. Li, W. Fan, A. Gasser, W. Huang, The influence of Laves phases on the room temperature tensile properties of Inconel 718 fabricated by powder feeding laser additive manufacturing, Acta Mater. 164 (2019) 413-427. https://doi.org/10.1016/j.actamat.2018.10.032.

[19] J.J. Schirra, R.H. Caless, R.W. Hatala, The Effect of Laves Phase on the Mechanical Properties of Wrought and Cast + HIP Inconel 718, (2012) 375-388. https://doi.org/10.7449/1991/superalloys_1991_375_388.

[20] H. Xiao, S. Li, X. Han, J. Mazumder, L. Song, Laves phase control of Inconel 718 alloy using quasi-continuous-wave laser additive manufacturing, Mater. Des. 122 (2017) 330-339. https://doi.org/10.1016/j.matdes.2017.03.004.

[21] S.G.K. Manikandan, D. Sivakumar, M. Kamaraj, Influence of weld cooling rate, 2019. https://doi.org/10.1016/b978-0-12-818182-9.00004-9.

[22] F.R.N. Nabarro, Fifty-year study of the Peierls-Nabarro stress, Mater. Sci. Eng. A. 234-236 (1997) 67-76. https://doi.org/10.1016/s0921-5093(97)00184-6.

[23] E. Hosseini, V.A. Popovich, A review of mechanical properties of additively manufactured Inconel 718, Addit. Manuf. 30 (2019) 100877. https://doi.org/10.1016/j.addma.2019.100877.

[24] H.L. Eiselstein, Metallurgy of a Columbium-Hardened Nickel-Chromium-Iron Alloy, in: Adv. Technol. Stainl. Steels Relat. Alloy., ASTM International, 100 Barr Harbor Drive, PO Box C700, West Conshohocken, PA 19428-2959, 1965: pp. 62-62-18. https://doi.org/10.1520/STP43733S.

[25] M.C. Chaturvedi, Y. Han, Strengthening mechanisms in Inconel 718 superalloy, Met. Sci. 17 (1983) 145-149. https://doi.org/10.1179/030634583790421032.

[26] M. Sundararaman, P. Mukhopadhyay, S. Banerjee, Precipitation of the $\delta$-Ni3Nb phase in two nickel base superalloys, Metall. Trans. A. 19 (1988) 453-465.

https://doi.org/10.1007/BF02649259.

[27] M. Sundararaman, P. Mukhopadhyay, S. Banerjee, Some aspects of the precipitation of metastable intermetallic phases in INCONEL 718, Metall. Trans. A. 23 (1992) 2015-2028. https://doi.org/10.1007/BF02647549.

[28] M. Wang, M. Song, G.S. Was, J.L. Nelson, The roles of thermal mechanical treatment and $\delta$ phase in the stress corrosion cracking of alloy 718 in primary water, Corros. Sci. 160 (2019) 108168. https://doi.org/10.1016/j.corsci.2019.108168.

[29] S. Mahadevan, S. Nalawade, J.B. Singh, A. Verma, B. Paul, K. Ramaswamy, Evolution of $\delta$ phase microstructure in alloy 718, 7th Int. Symp. Superalloy 718 Deriv. 2010. 2 (2010) 737-750. https://doi.org/10.1002/9781118495223.ch57.

[30] Standard Specification for Precipitation-Hardening Nickel Alloy (UNS N07718) Plate, Sheet, and Strip for High-Temperature Service, Annu. B. ASTM Stand. 07 (2010) 7-10. https://doi.org/10.1520/B0670-07. 
[31] M.N. Gussev, R.H. Howard, K.A. Terrani, K.G. Field, Sub-size tensile specimen design for inreactor irradiation and post-irradiation testing, Nucl. Eng. Des. 320 (2017) 298-308.

https://doi.org/10.1016/j.nucengdes.2017.06.008.

[32] A.G. Le Coq, R.H. Howard, K.D. Linton, K.G. Field, Design and Thermal Analysis for Irradiation of Tensile Specimens from Wrought, Powder Metallurgy, and Additive Processed Alloys in the HFIR, (2018). https://doi.org/10.2172/1474529.

[33] C.M. Parish, N.A.P. Kiran Kumar, L.L. Snead, P.D. Edmondson, K.G. Field, C. Silva, A. Marie Williams, K. Linton, K.J. Leonard, LAMDA: Irradiated-Materials Microscopy at Oak Ridge National Laboratory, Microsc. Microanal. 21 (2015) 1003-1004. https://doi.org/10.1017/s1431927615005814.

[34] G. Cliff, G.W. Lorimer, The quantitative analysis of thin specimens, J. Microsc. 103 (1975) 203207. https://doi.org/10.1111/j.1365-2818.1975.tb03895.x.

[35] J. Schindelin, I. Arganda-Carreras, E. Frise, V. Kaynig, M. Longair, T. Pietzsch, S. Preibisch, C. Rueden, S. Saalfeld, B. Schmid, J.Y. Tinevez, D.J. White, V. Hartenstein, K. Eliceiri, P. Tomancak, A. Cardona, Fiji: An open-source platform for biological-image analysis, Nat. Methods. 9 (2012) 676-682. https://doi.org/10.1038/nmeth.2019.

[36] M.J. Donachie, S.J. Donachie, Superalloys: A Technical Guide, 2nd Edition, 2nd Editio, ASM International, 2002.

[37] A. Oradei-Basile, J.F. Radavich, A Current T-T-T Diagram for Wrought Alloy 718, in: E.A. Loria (Ed.), Superalloys 718, 625, Var. Deriv., The Minerals, Metals \& Materials Society, 1991: pp. 325-335. https://doi.org/10.7449/1991/superalloys_1991_325_335.

[38] J.F. Radavich, The Physical Metallurgy of Cast and Wrought Alloy 718, in: Superalloys 718 Metall. Appl., TMS, 2004: pp. 229-240. https://doi.org/10.7449/1989/Superalloys_1989_229_240.

[39] A. Segerstark, J. Andersson, L.E. Svensson, O. Ojo, Microstructural characterization of laser metal powder deposited Alloy 718, Mater. Charact. 142 (2018) 550-559.

https://doi.org/10.1016/j.matchar.2018.06.020.

[40] G.F. Knoll, Radiation Detection and Measurement, 3rd Editio, John Wiley \& Sons, Inc., 2000.

[41] K. Yuan, W. Guo, P. Li, Y. Zhang, X. Li, X. Lin, Thermomechanical behavior of laser metal deposited Inconel 718 superalloy over a wide range of temperature and strain rate: Testing and constitutive modeling, Mech. Mater. 135 (2019) 13-25. https://doi.org/10.1016/j.mechmat.2019.04.024.

[42] T. Yonezawa, Nickel-Based Alloys, in: Compr. Nucl. Mater., Elsevier, 2020: pp. 319-354. https://doi.org/10.1016/B978-0-12-803581-8.00676-7.

[43] S.G.K. Manikandan, D. Sivakumar, M. Kamaraj, Physical metallurgy of alloy 718, Weld. Inconel 718 Superalloy. (2019) 1-19. https://doi.org/10.1016/b978-0-12-818182-9.00001-3.

[44] T.S. Byun, K. Farrell, Tensile properties of Inconel 718 after low temperature neutron irradiation, J. Nucl. Mater. 318 (2003) 292-299. https://doi.org/10.1016/S0022-3115(03)00006-0.

[45] H.M. Ledbetter, R.P. Reed, Elastic Properties of Metals and Alloys, I. Iron, Nickel, and IronNickel Alloys, J. Phys. Chem. Ref. Data. 2 (1973) 531-618. https://doi.org/10.1063/1.3253127.

[46] S. Umekawa, On Young's Moduli of Nickel-Copper and Nickel-Cobalt Alloys, J. Japan Inst. Met. 18 (1954) 387-390. https://doi.org/10.2320/jinstmet1952.18.7_387. 
[47] Y. Shirakawa, K. Numakura, Elasticity Constants of Single Crystals of Nickel-Copper Alloys, Sci. Reports Res. Institutes, Tohoku Univ. Ser. A, Physics, Chem. Metall. 10 (1958) 51-57. http://hdl.handle.net/10097/26859.

[48] Y. Shirakawa, K. Numakura, On Young's Modulus and Grain Size in Nickel-Copper Alloys, Sci. Reports Res. Institutes, Tohoku Univ. Ser. A, Physics, Chem. Metall. 10 (1958) 110-119. http://hdl.handle.net/10097/26866.

[49] Y. Shirakawa, Y. Tanji, H. Moriya, I. Oguma, The Elastic Constants of Ni and Ni-Fe (fcc) Alloys, Sci. Reports Res. Institutes, Tohoku Univ. Ser. A, Physics, Chem. Metall. 21 (1969) 187-200. http://hdl.handle.net/10097/27496.

[50] M. Yamamoto, On Elastic Constants of Nickel Crystals, Phys. Rev. 77 (1950) 566-566. https://doi.org/10.1103/PhysRev.77.566.

[51] H. Masumoto, H. Saito, S. Sawaya, Thermal Expansion and Temperature Dependence of Young's Modulus of Nickel-Copper Alloys, Trans. Japanese Inst. Met. 11 (1970). 
(a) 